\title{
Conclusion: Paradise Lost
}

Christy Davis

Symphony in the Flint Hills, Inc.

Follow this and additional works at: https://newprairiepress.org/sfh

\section{Recommended Citation}

Davis, Christy (2018). "Conclusion: Paradise Lost," Symphony in the Flint Hills Field Journal. https://newprairiepress.org/sfh/2018/structure/6

To order hard copies of the Field Journals, go to shop.symphonyintheflinthills.org.

The Field Journals are made possible in part with funding from the Fred C. and Mary R. Koch Foundation.

This Event is brought to you for free and open access by the Conferences at New Prairie Press. It has been accepted for inclusion in Symphony in the Flint Hills Field Journal by an authorized administrator of New Prairie Press. For more information, please contact cads@k-state.edu. 


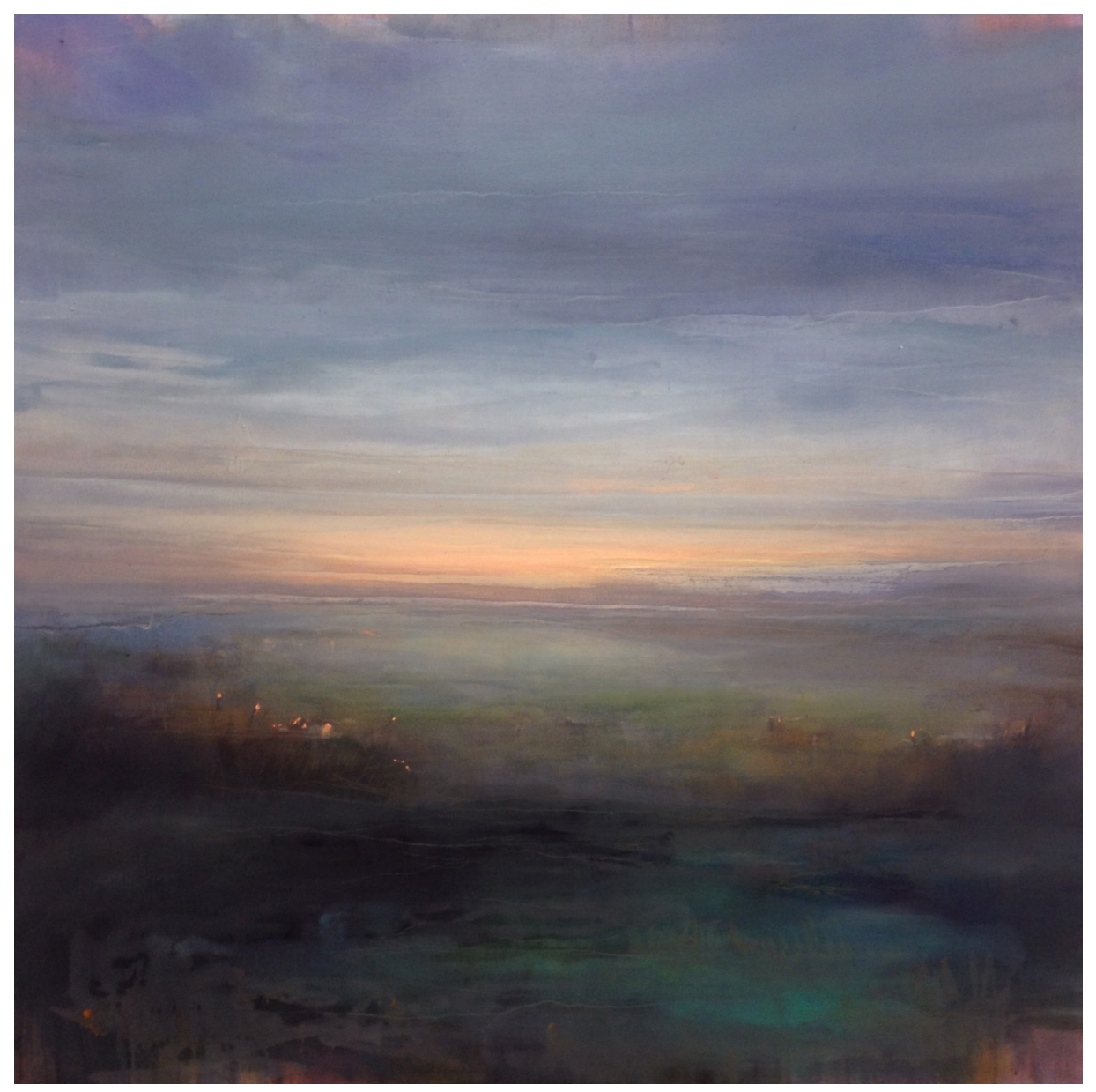

The first white men to see the Texas Hill Country described it as a paradise. The tall grass "stretched as far as the eye could see, covering valleys and hillsides alike" with random trees "rising out of a rippling pale green sea."

"There was almost no brush, and few small trees - only the big oaks and the grass as if [it] were a landscaped park." "Springs gushed out of the hillsides, and streams ran through the hills ... And the streams ... were full of fish." The Hill Country was a land rich in grass and water, a land made for grazing.

To nineteenth-century pioneers, grass and water signaled one thing: a good place to plow and plant. But attempts to farm the Hill Country upended a millennia-long fine balance. In the words of Robert Caro, "It was rich only because it was virgin. And it could be virgin only once." "The Hill Country," Caro observed, "was a trap baited with water and grass."

It's been twenty years since I first read Robert Caro's rich description of Lyndon B. Johnson's Texas Hill Country. My first visit to the region in 1998 was tainted by the miles of unchecked urban sprawl that streamed by while I rode for hours on the wrong Austin bus. A decade later, I had the opportunity to visit the farther reaches of the Hill Country and was happy to see that many of the ranches, rural dance halls and quaint small towns still maintained a refreshing authenticity.

When I read Caro's portrayal of the Hill Country, I can't help but compare it to the Kansas Flint Hills. Like the Flint Hills, the 
Texas Hill Country was formed of fire. Once they stopped burning the prairie, the early settlers were shocked at how quickly the landscape changed. "The early settlers ... couldn't believe how fast the brush spread ... from one year to the next, whole sections of land changed When white men first came into the Hill Country, there was little cedar there. Twenty years later, cedar covered whole areas of the country as far as the eye could see; by 1904 , a single cedar brake reaching northwest from Austin covered 500 square miles - and was growing, faster and faster, every year. And every acre of brush meant an acre less of grass."

Like the Flint Hills, the Texas Hill Country was built on trust - trust that you and your neighbor would make decisions on the shared premise of multi-generational pride in the region's rich landscape and culture. A culture of trust and homogeneity has no need for regulation. The unwritten rules are understood. You and your neighbors burn in April, you spend winters cutting down cedar trees, and you keep the ranch in the family.

But my most recent visit to the Hill Country in September 2017 has me thinking about what happens in the Flint
Hills when the cultural seal is broken and the flood gates are thrown open. If the

Hill Country of the nineteenth century was a trap baited with grass and water, the Hill Country of the twenty-first century

is a trap baited with the trappings of a mythical ranching lifestyle that few can afford. Gated subdivisions in places like the once-quaint Fredericksburg and Dripping Springs are marketed as "luxury ranch real estate," with views of rolling hills and rambling wildlife, near "country casual" music venues.

What was once a paradise is now an endless sea of crackerbox houses whose appropriateness is justified by a thin veneer of native limestone. This is the very palpable consequence of loving a landscape too much. Since 2000 the population of Travis County, Texas, alone has grown by 380,000 . And every acre of homes means an acre less of grass.

In both the Texas Hill Country and the Kansas Flint Hills, a culture of trust and self-reliance chafes against regulation.

Shouldn't every man be allowed to make decisions about the land he owns? Shouldn't anyone be able to build a house anywhere along a rural water line? While we ponder these questions, the tallgras

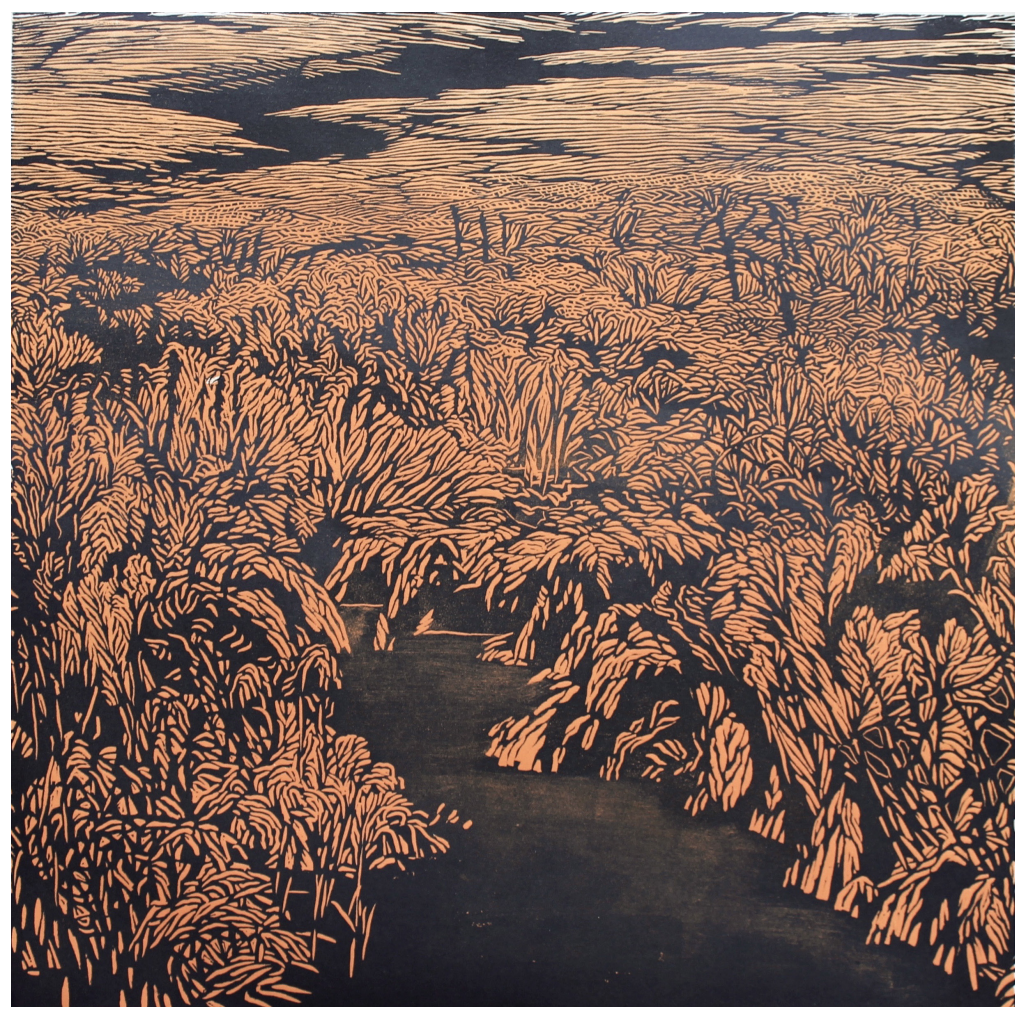

prairie is being eroded in increments of five-acre ranchettes.

If rural communities are making decisions based on severely limited resources - both financial and natural they cannot ignore rural sprawl. Defined as "an inefficient, expansive use of rural and for hobby farms, acreages, and other small-scale, low-productivity properties," rural sprawl has a lifetime cost of up to 400 times that of denser development.

Ten years ago, Texans took notice of the rapid change in their physical surroundings and the drain of rural sprawl on their precious water resources. Concerned citizens formed the Hill Country Alliance, an advocacy group with the "objective of preserving open spaces, 
water supply, water quality, and the unique character of the Texas Hill Country." But worry that it may be too little too late.

I used to hold the naive belief that what happened in the Texas Hill Country could never happen in the Flint Hills.

Who would invest that kind of money in rural Kansas? But in this place where multi-generational ranchers are forced to make tough economic choices and small towns are in a state of decline, some communities will welcome investment at any cost. In order to regulate others, we would have to regulate ourselves. And, besides, we don't want to stand in the way of progress.

If most of us agree that grazing is the highest and best use of the richest grassland in the world, why do we allow the land to be developed without thinking about the consequences? If we build homes, we can't burn, if we can't burn, we'll be swamped with cedar trees, if cedar trees choke out the grass, water won't flow through our streams. If the Flint Hills

becomes a region filled with subdivisions named after the ranches that used to be here, is it still the Flint Hills? If we pave the grasslands, what will we lose?

Texas knows the answers. Texas learned the hard way that once you identify a place as paradise, it moves one step closer to becoming paradise lost.

The people of the Flint Hills will decide whether future generations will inherit "North America's characteristic landscape." Will springs gush from the hillsides and streams run through the hills, or will we allocate non-renewable water resources in this precariously balanced place to feed inefficient and inappropriate development. They say water is the universal solvent; could it also be a universal solver? Like the Texas Hill Country, perhaps we should begin the conversation with water. But let's not wait until it's too late.

Christy Davis, Executive Director,

Symphony in the Flint Hills
FOLLOWING SPREAD Winter Wetland

Dave Leiker 


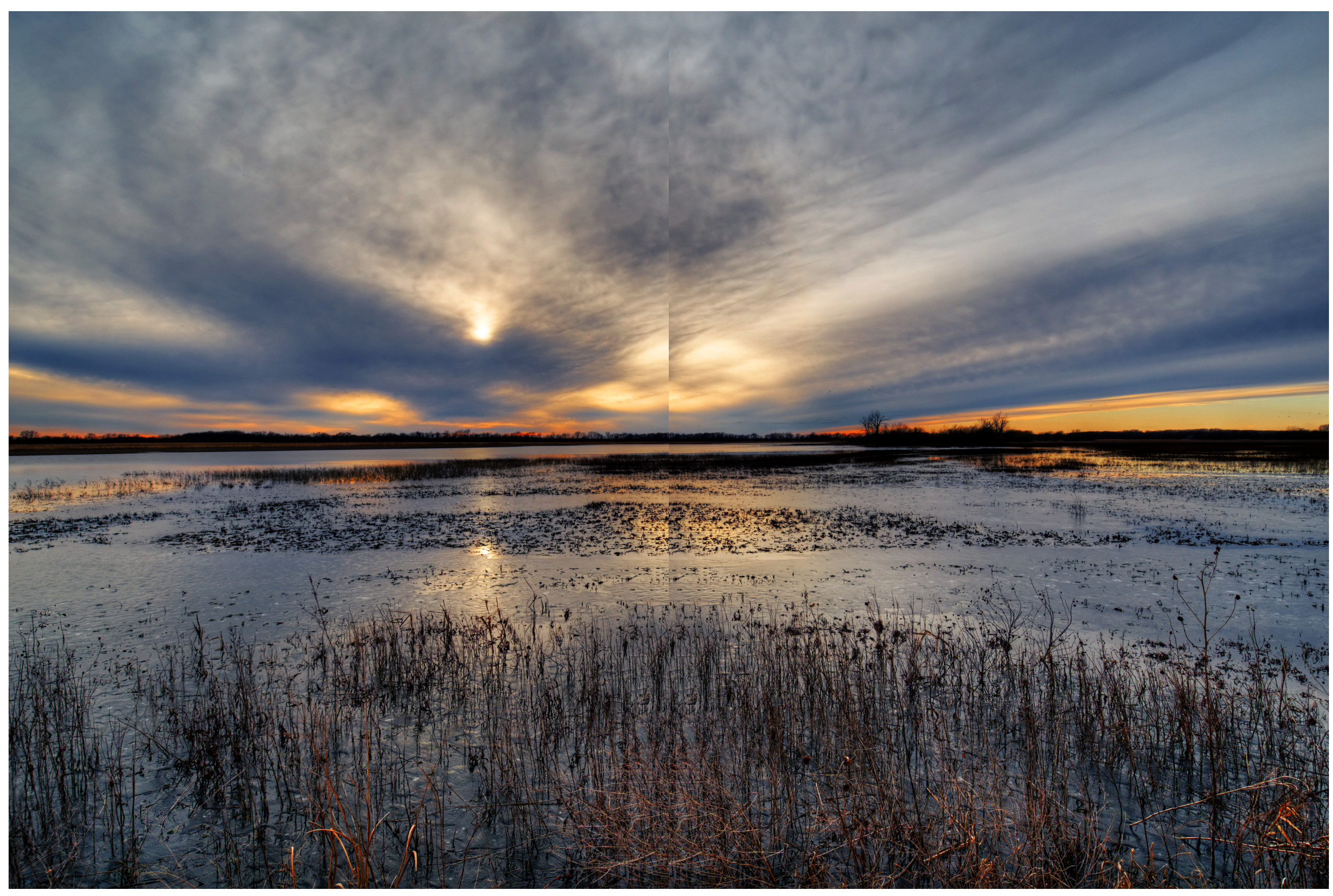

